\title{
Using BIM for the Assessment of the Seismic Performance of Educational Buildings
}

\author{
Carmen Angulo ${ }^{1}$, Karen. Díaz ${ }^{1}$, José M. Gutiérrez ${ }^{1}$, Andrea Prado ${ }^{1}$, Rosanna Casadey ${ }^{1}$, Gino Pannillo ${ }^{1}$, Felipe Muñoz-La \\ Rivera $^{2,3}$, Rodrigo F. Herrera ${ }^{2,4,5}$, Juan C. Vielma ${ }^{2 *}$ \\ ${ }^{1}$ Universidad Centroccidental Lisandro Alvarado, Venezuela, Av. Las Industrias, Barquisimeto 5001, Venezuela \\ ${ }^{2}$ Pontificia Universidad Católica de Valparaíso, School of Civil Engineering, Av. Brasil 2147, Valparaíso, Chile \\ ${ }^{3}$ Universitat Politècnica de Catalunya, School of Civil Engineering, Carrer de Jordi Girona, 1, 08034, Barcelona, Spain \\ ${ }^{4}$ Pontificia Universidad Católica, Production Management Centre, Vicuña Mackena 4860, Santiago, Chile \\ ${ }^{5}$ Universitat Politècnica de València, School of Civil Engineering, Camino de Vera s/n, Valencia, Spain
}

Corresponding Author Email: juan.vielma@pucv.cl

https://doi.org/10.18280/ijsse.100110

Received: 7 June 2019

Accepted: 31 July 2019

\section{Keywords:}

BIM, seismic assessment, FEMA P-58, non-linear analysis, performance groups, fragility curves

\begin{abstract}
The progress of the study of seismic vulnerability has allowed the formulation of new assessment methodologies, which take into account not only the behaviour of the structural and non-structural elements, but also the components that, due to their importance and cost, can represent an investment that in some cases becomes greater than the cost of the whole building. To carry out this more specific type of study, it is necessary to use tools that allow estimating, locating and properly characterizing the components, which has been a problem that has not yet been solved, due to the inability to maintain together all the components in a single model of a building. This paper presents the results of a research in which BIM procedures have been combined to overcome these deficiencies, successfully implementing it in the assessment of the seismic vulnerability of a set of university buildings which have been built in the middle of 1970's and 2000's, improving the quality of the information necessary to perform the numerical simulations and the consequent quantification of the damage that allowed obtaining the required repair costs, under the scenario of the occurrence of a maximum probable earthquake.
\end{abstract}

\section{INTRODUCTION}

After the occurrence of recent strong earthquakes, the adequate seismic behaviour of the structures has been verified, which however has not guaranteed that the losses achieved are satisfactory from of all the people involved within the project's life. For this reason, particular emphasis has been placed on the use of new methods to design structures such as the performance-based method and the adequacy of existing structures, after carrying out an adequate assessment of vulnerability through appropriate methods. The new objective is to ensure that the structural response allows the preservation of damage to the structural, non-structural elements and contents of the building so that losses can be minimized.

FEMA P-58 [1] is one of the tools that allow quantifying the losses that can be achieved during an earthquake, proposing for this a methodological framework that combines deterministic and probabilistic procedures.

The use of very sophisticated analysis tools, which require a complete description of the attributes of the components that will be evaluated based on their response and associating this to different types of fragility, has a high complexity associated with the definition of the model. BIM-based tools have already been used to efficiently manage this complexity, reducing the time spent managing information and centralizing it in a single model, which allows detecting possible interferences or incompatibilities.

On the other hand, according to recent work [2], the potential present in BIM to support the development of seismic risk assessment procedures is based on the following three areas:

- $\quad$ BIM allows to provide characteristics of the structural and non-structural elements, allowing the holistic evaluation of the seismic risk.

- Facilitate self-diagnosis processes in phases before and after an earthquake.

- $\quad$ Enabling a monitoring center for system master components, which can be stopped when the system collapses.

Although the advantages offered by the BIM platform for the development of projects and their management throughout their useful life are acknowledged, there are very few reports of their use in the field of performance evaluation against events. destructive environmental, such as earthquakes. In a recent work [3] a prototype office building was studied by using the FEMA P-58 methodology. In this work, the model was exported directly from the chosen BIM platform to the non-linear analysis program Opensees, which allows interoperability. The authors managed to integrate the model generation procedure with different stages of the evaluation.

Through the study of the complex structural configurations of a historic masonry building [4], the authors used BIM to establish the link between the raised model and the finite element model used to perform the structural analysis. It has also been proposed to use BIM to evaluate the seismic vulnerability of non-structural elements [5].

In other recent work [6] applying the same evaluation methodology, they identified the high level of detail required to define the model to be analyzed, based on the different 
levels of development for the building components and extracting the information using the application programming interface (API) contained in the Autodesk Revit program. The main achievement of this work was to produce a reliable loss assessment, even though limited data was available on the information of the analyzed building.

Incorporating the BIM platform has been the solution proposed by Villa et al. [7] to face the challenge of carrying out the evaluation of the seismic vulnerability of the stock of educational buildings in Italy. In the proposed methodology, it is recommended to generate common models according to the different types of buildings, the date of construction, the type and quality of the materials of the structure, among others. Based on the models generated, the methodology contemplates two different approaches, one that proposes a qualitative evaluation of the data of the model and another one in which it is decided on the data collected by sensors placed in the structure in order to carry out the monitoring.

In another direct use of BIM technologies [8], the authors have studied the incorporation of these technologies in the optimization process within the offices that carry out structural engineering projects in Chile, indicating the favorable impact within these processes.

\section{ASSESSMENT METHODOLOGY}

The used methodology consists of the well documented FEMA P-58 in which a comprehensive procedure is formulated in order to assess the seismic vulnerability of building according to three different types of definition of the seismic action:

- Intensity-based assessment

- $\quad$ Scenario-based assessment

- Time-based assessment

Figure 1 shows the flowchart which summarized the assessment methodology.

In applying the methodology's first step, it is necessary to define the whole model of the building that needs to be analyzed. This definition includes the classic modelling of the structural components, as well as the non-structural elements and the components and, finally, the occupation by the users of the building. In this stage, it is necessary to define the location of every component in order to take into account the actions the earthquake ground motion imposes and so determine the associated loses.

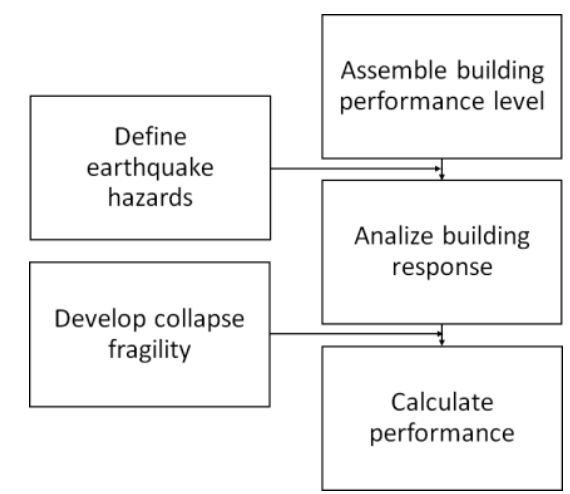

Figure 1. Flowchart of the assessment methodology according to FEMA P-58

All vulnerable structural, non-structural and content components are categorised into fragility groups and performance groups. The number of components and contents within a building and belonging to each performance group can be determined from a specific inventory. The number and distribution of the components that conform to each selected fragility specification is entered in PACT (computational tool provided by FEMA P-58) through the definition of Performance Groups in each floor, Figure 2. This group is defined as a set of components described by a single fragility group that will experience the same demand. And they are organised by the application direction of their common seismic-demand parameter.

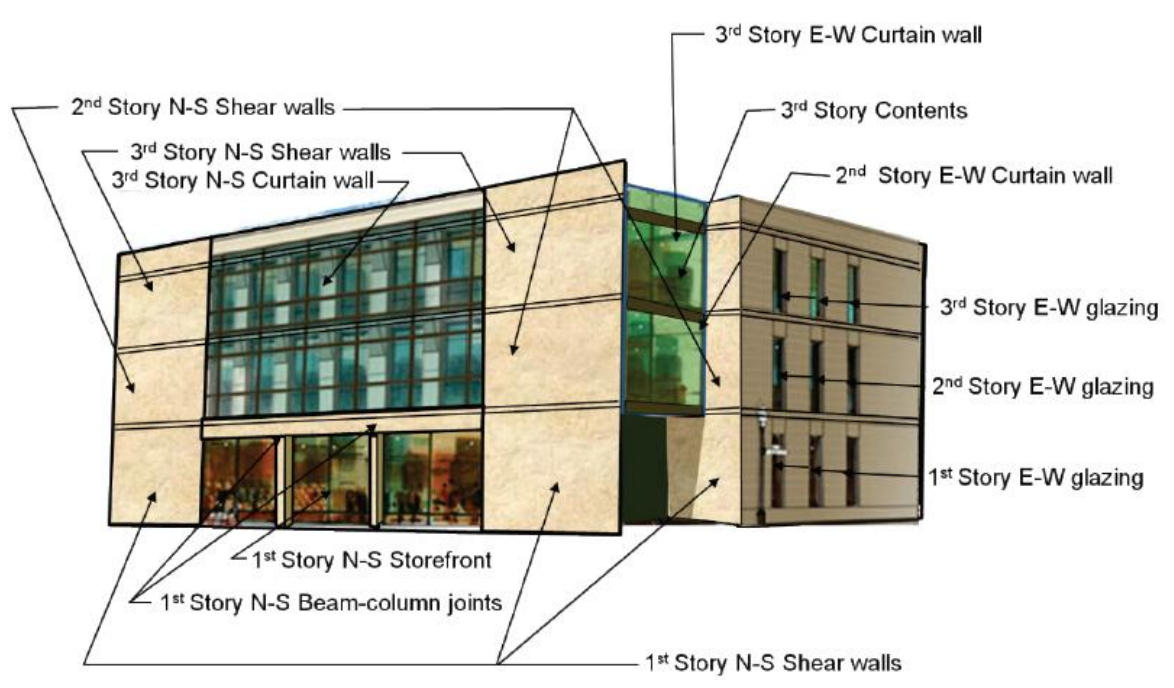

Figure 2. Example of performance groups [1]

The methodology provides a tool for the calculation of normative quantities of different buildings depending on the model of population taken, number of levels and area of each floor, where it indicates the dispersion associated with each component. However, this tool was not used in the present study, since the quantification of each component has been carried out in detail by each level of the building and then this information has been incorporated into the BIM model of each building. To calculate the losses of each component contained in the building, it is necessary to define fragility curves, which allow associating the damage at different levels of seismic demands. These fragility curves have been developed based on 
experimental data obtained in the laboratory. Figure 3 shows an example of the fragility function used.

Fragility functions are contained in FEMA P-58 documentation, specifically in the PACT, which depicts the seismic demand data resulting from the non-linear analysis. With this data, a series of realisations must be obtained applying the Monte Carlo simulation, which ensures obtaining a higher number of results for a specific characteristic.

In using FEMA P58 methodology, it is important to define the type of information required about the building. The most relevant information is: geometry or size, replacement cost and replacement time. It is also important to define the occupation of the building, with the distribution of people throughout the day, through an envelope curve that takes into account the variability in occupation. Within the occupation, it is necessary to define the types of non-structural components and contents (equipment and furniture) that are inside the building.

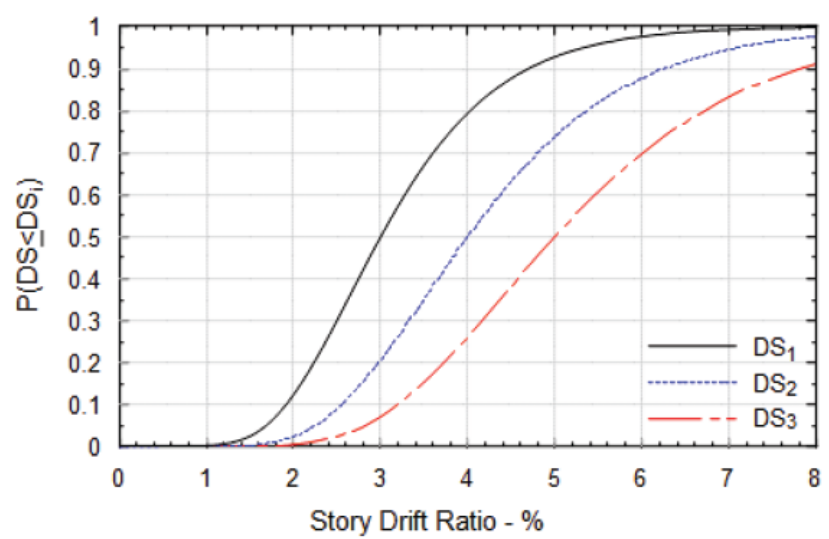

Figure 3. Example of fragility function [1]

The identification of vulnerable structural elements and assemblies is required, with a level of detail that allows the quantification of the damage that will occur during the action of the earthquake. Damages to these elements and structural assemblies are measured in terms of collapse potential and the potential for generating debris that causes injuries and that causes the need for repairs.

Finally, for vulnerable non-structural systems, components and contents, the information should be kept in sufficient detail to identify its location within the building and the demands imposed by the earthquake.

As it has been enumerated previously, it is evident that the assembly of the performance model of the building can become an arduous and difficult task to carry out if it does not perform on a work platform that allows registering of efficient form the location of all the elements structural, non-structural and contents. That is why, in the context of the work of assessing the seismic vulnerability of buildings, it has been decided to start from a model in which all this information can be recorded, for which the Building Information Modelling technology has been used. BIM) with the added purpose of obtaining a usable structural model for the next phase of the work, consisting of the analysis of the building response.

The performance model of the building is generated taking into account the population model, fragility groups and performance groups. Figure 4 shows the population model corresponding to building $\mathrm{C}$, which represents the number of people per $1,000 \mathrm{sqf}\left(92.90 \mathrm{~m}^{2}\right)$ of the area inside the building.

The losses are calculated based on the damage that is achieved in structural, non-structural elements and building components. To calculate the damage, it is necessary to group each of these elements and components into performance groups, which are usually characterised as being affected mainly by some specific demand by the strong ground motion.

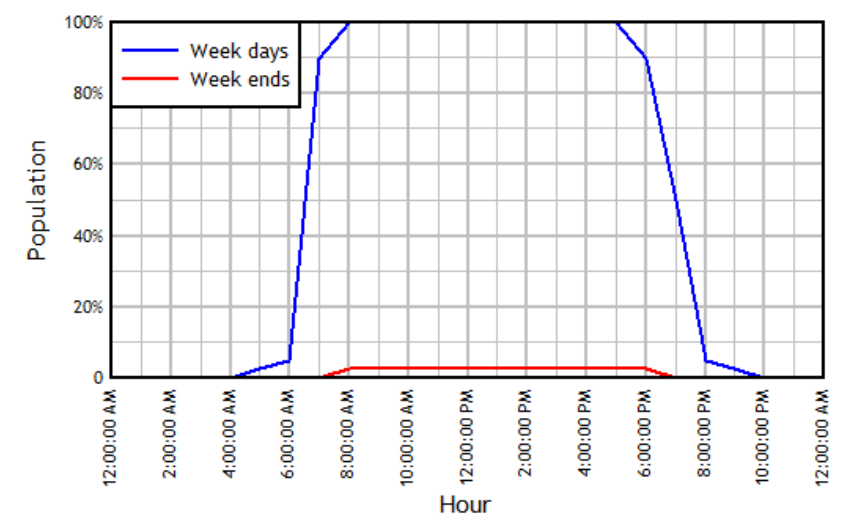

Figure 4. Population Model, weekly concentration per hour

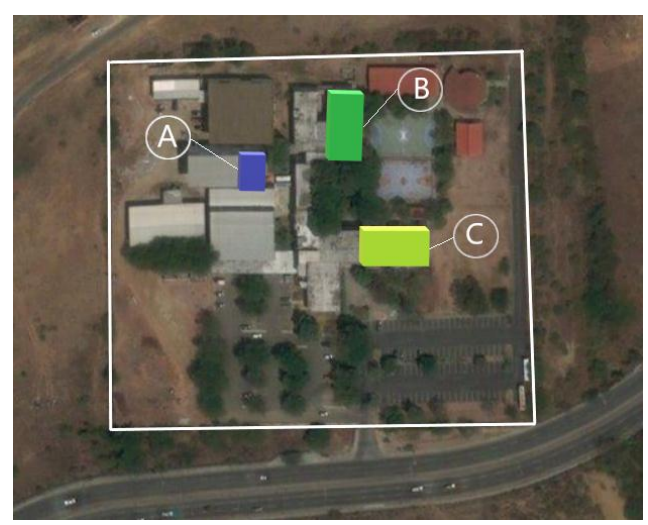

Figure 5. View of Civil Engineering campus master plan with the location of the three building studied

\section{DESCRIPTION OF THE BUILDINGS STUDIED}

For this research, three buildings have been selected that make up the university complex of the Faculty of Civil Engineering of the Lisandro Alvarado University, located in the city of Barquisimeto. These buildings have been built at different dates, so they have been designed according to different construction codes. Figure 5 shows the campus master plan view, with the location of the three buildings taken as cases for this study. These buildings are identified as building $\mathrm{A}$, building $\mathrm{B}$ and building $\mathrm{C}$, whose relevant information is summarized in Table 1 and $3 \mathrm{D}$ views of each building is shown from Figure 6 to 8 .

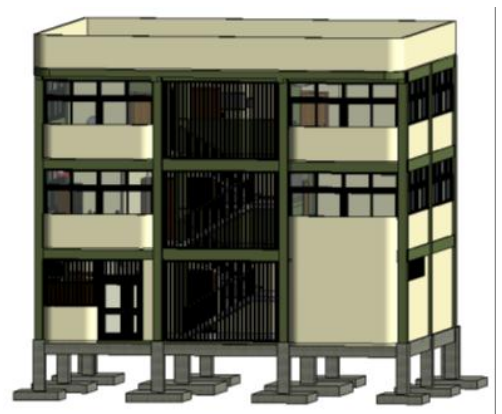

Figure 6. 3D view of the model of Building A 


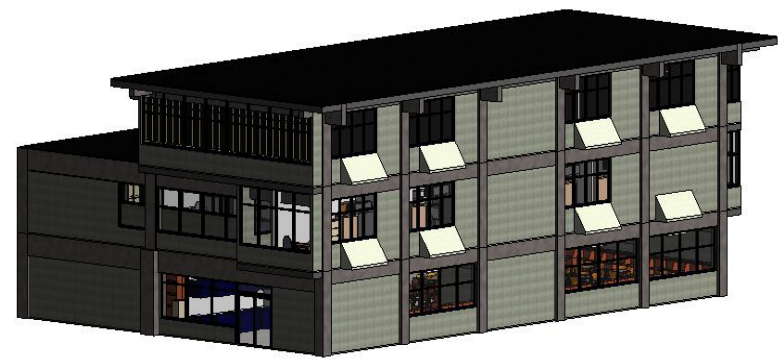

Figure 7. 3D view of the model of Building B

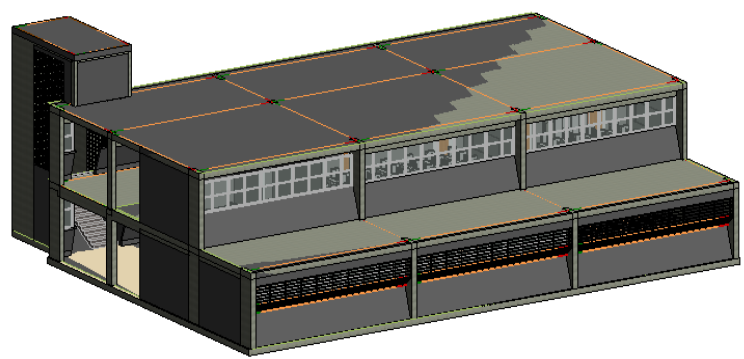

Figure 8. 3D view of the model of Building C

Table 1. Summary of the buildings characteristics

\begin{tabular}{lccccc}
\hline & Date & $\mathbf{N}^{\circ}$ of stories & Area $\left(\mathbf{m}^{2}\right)$ & Structure & Main use \\
\hline Building A & 2003 & 3 & 130 & RC-framed & Office, Laboratory controls and professors' offices \\
Building B & 2001 & 3 & 1,155 & RC-framed & Library, post-graduated classrooms and computation laboratories \\
Building C & 1977 & 2 & 930 & RC-framed & Classrooms and offices \\
\hline
\end{tabular}

\section{RESULTS}

The buildings studied have been subjected to nonlinear static analysis. For this purpose, they have been modelled using the SeismoStruct software [9]. The modelling requires the detailed definition of the structural components, which has been obtained from the survey of the original projects of each building. As the buildings present a certain structural irregularity associated mainly with the plants, it has been necessary to use the $\mathrm{N} 2$ procedure [10] to adjust the displacements reached the different levels.

To determine the non-linear response of the three buildings analyzed, these have been modelled using a finite element program based on fibers. In Figure 9 the model generated for Building B is shown, with the lateral loads used to simulate the action of the earthquake in the $\mathrm{x}$-direction.

Nonlinear static analysis results in the building capacity curve for each analysis direction. This curve must be linearized, so that it can be used later in the SPO2IDA procedure [11] that will convert it into an IDA curve. The linearization procedure is based on a recent work [12] see Figure 10.

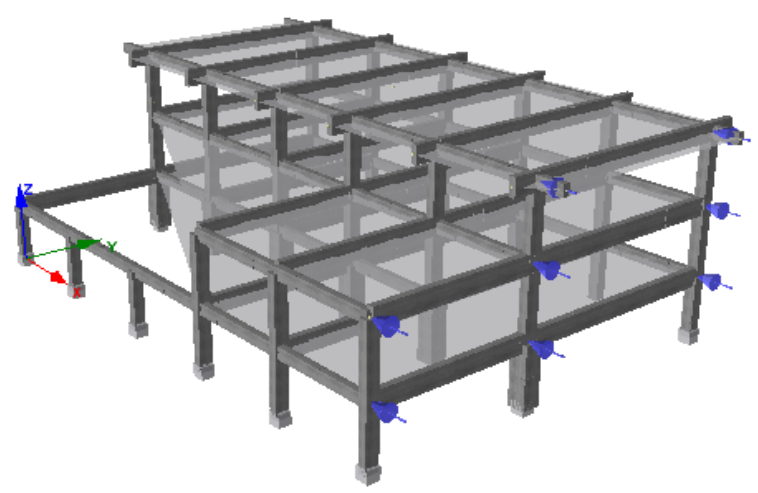

Figure 9. Perspective view of the model for non-linear static analysis applied to Building B

FEMA P-58 methodology includes a procedure to determine the collapse threshold of a building. This is based on the results of the dynamic incremental analysis [13]. This type of analysis is currently recognized by the international community as the most sophisticated and accurate to assess the vulnerability of structures subjected to strong ground motion. However, they have the disadvantage that it is a type of analysis with a high computational cost, which makes its use very limited to cases that justify it. For this reason, in a work referenced in FEMA P-58, the concept of obtaining IDA curves through the results of static nonlinear analysis has been introduced. This procedure is simple and allows to determine the simulated curves for three different percentiles. IDA curves obtained from building B are shown in Figure 11.

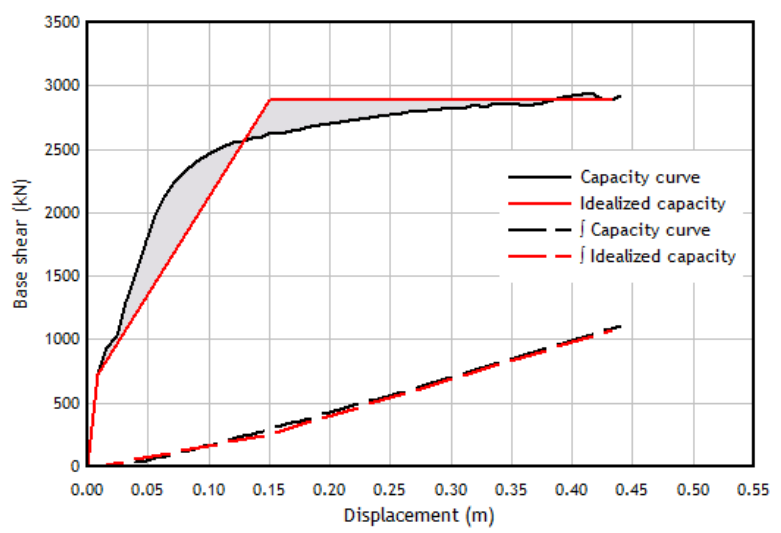

Figure 10. Capacity curve and idealized capacity obtained according to dissipated energy equilibrium [11]

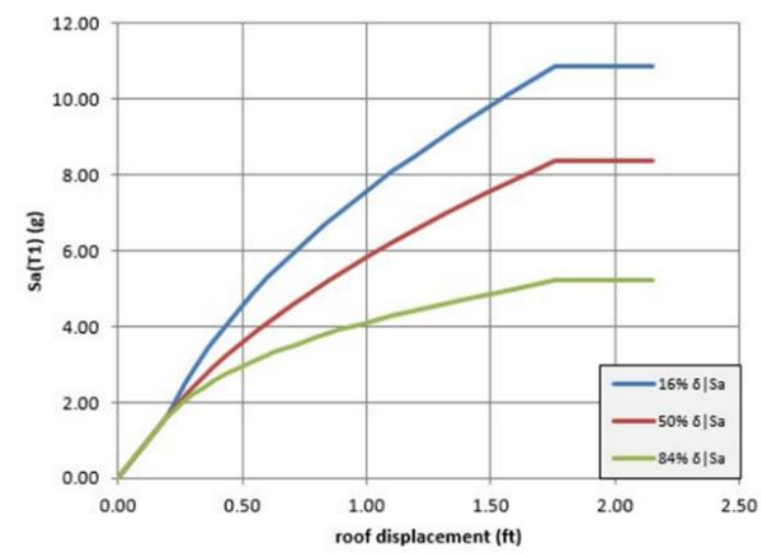

Figure 11. IDA curves of building B in $\mathrm{x}$-direction obtained form SPO2IDA 


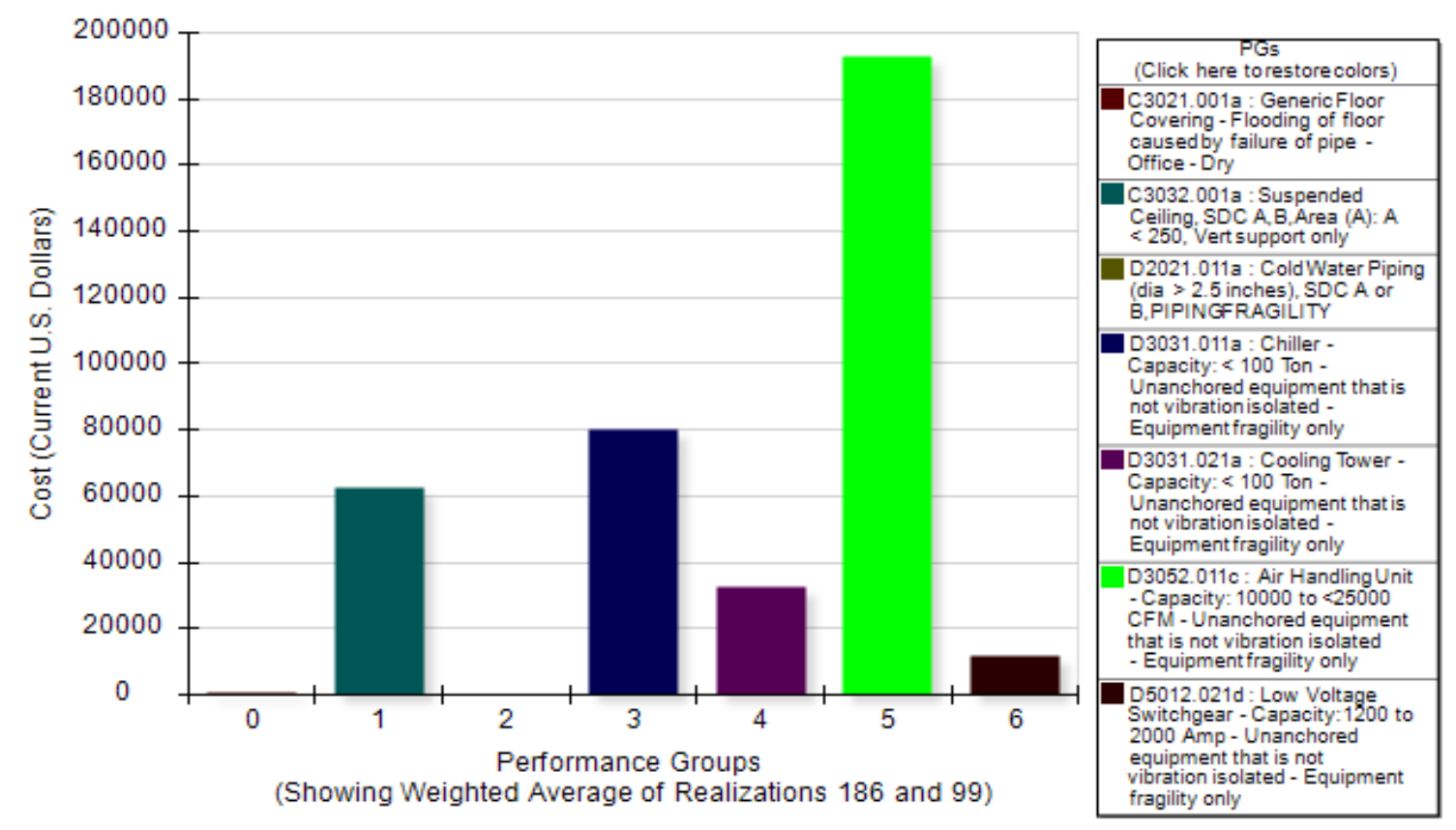

Figure 12. Simulation of the repair cost of each performance groups of building A, according to PACT

For each realization, it is determined whether the structure reaches a collapse or not. The probability of collapse is evaluated by applying the fragility function of collapse presented in FEMA P695 [14].

The calculation of the losses is carried out also using the realizations, which take into account the fragility functions of each defined performance group of the building, see Figure 12.
In each realization, the economy of scale and the efficiency of the construction are considered to determine the repair actions of the building. With the calculation of the total losses, it is possible to determine whether the buildings are repairable or not. If the buildings are classified as irreparable, a total replacement cost will be assigned and a time corresponding to the time required to demolish the building and rebuild it.

Table 2. Consequences on the buildings determined according the methodology

\begin{tabular}{lccccc}
\hline & Direct. & Repair cost (USD) & Repair time (days) & Number of injured & Number of casualties \\
\hline Building A & $\mathrm{x}$ & 380,000 & 51 & 1 & 8 \\
& $\mathrm{y}$ & 376,666 & 64 & 1 & 8 \\
Building B & $\mathrm{x}$ & 142,500 & 130 & 0 & 0 \\
& $\mathrm{y}$ & 125,000 & 116 & 0 & 0 \\
Building C & $\mathrm{x}$ & 609,876 & 460 & 21 & 187 \\
& $\mathrm{y}$ & 609,876 & 460 & 0 & 208 \\
\hline
\end{tabular}

The results summarized in Table 2 show that building C, being the oldest, was designed with code prescriptions that are obsolete by now. Therefore, it is the building with the greatest vulnerability to strong earthquakes in any of the two directions of analysis. On the other hand, it can be seen that building A presents a reduced number of deaths and injuries ( 8 and 1 respectively) in each of the directions of analysis. This is due to its more recent seismic design, with which repairable damages are reached at a reasonable cost. Finally, Building B shows a much more satisfactory overall performance, because there would be no deaths or injuries during its exposure to an earthquake similar to that envisaged in the current version of the Venezuelan seismic codes and the costs associated with the repair post-earthquake actions are relatively low, this shows that the conventional seismic design would not only protect the occupants, but also the structural, non-structural elements and contents of the B building.

Other important measure after a strong earthquake is the labelling of the building as unsafe to be occupied immediately. The methodology applied has made it possible to determine the probability that the performance groups that have been damaged may cause injuries, so the building must be sealed to prevent it from being occupied, thus controlling human losses. Figure 13 shows the probability of reach unsafe placard, when the analysis occurs in the $\mathrm{x}$-direction of building $\mathrm{A}$.

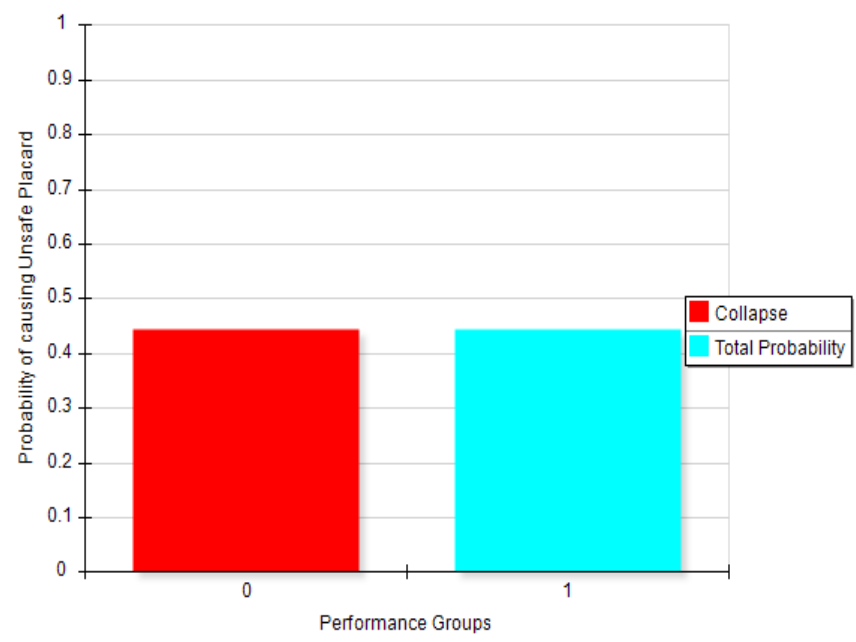

Figure 13. Probability of cause unsafe placard in building A for the $\mathrm{x}$-direction of analysis 


\section{CONCLUSIONS}

It is demonstrated in this research that by using a model defined in BIM it is possible to store in a single file the structural, non-structural elements and contents of the buildings object of the study. The information that has been saved consists of the location, as well as attributes related to the groups of fragility and benefits of each element, as well as its cost

Although the implementation of BIM has made it possible to perform the complex tasks of the FEMA P58 methodology more efficiently and accurately, it would be interesting that there could be interoperability between the program from which the model of the building is made and the program chose to carry out the non-linear analysis, improving the working time and reducing the possibilities of making mistakes in the generation process of the structure with the level of details required for the non-linear analysis using fibrebased models.

The use of FEMA P-58 with BIM tools allows the owners of buildings to make appropriate decisions before the occurrence of destructive earthquakes, preventing injuries and deaths, while reducing economic losses and the time necessary to carry out the repairs necessary to put the building into operation.

As a recommendation, it is suggested to organize the activities of the evaluation of the seismic vulnerability of buildings through the BIM platform, so that the performance groups are correctly located in order to determine the damage that can be achieved under a specific scenario. Similarly, given the high level of detail required by the FEMA P-58 Methodology, it is recommended to manage in a single model all the information of the structural, non-structural and component elements, thus avoiding rework and loss of information.

\section{ACKNOWLEDGMENT}

The authors wish to acknowledge to Universidad Centroccidental Lisandro Alvarado, in whose buildings this study has been carried out. Also to Pontificia Universidad Católica de Valparaíso, where three of the co-authors are researchers and professors. The last three authors also thank to Proyecto CORFO 14ENI2-26905 Ingeniería 2030-PUCV for their support in financing assistance to BIM2019. Prof. Herrera acknowledge to CONICYT - PCHA/National Doctorate/2018 - 21180884 for funding the graduate research.

\section{REFERENCES}

[1] FEMA. (2012). Seismic Performance assessment of buildings - Implementation guide. FEMA P-58-2, Washington, D.C.: Federal Emergency Management Agency.

[2] Welch, D.P., Sullivan, T.J., Filiatrault, A. (2014). Potential of building information modelling for seismic risk mitigation in buildings. Bulletin of the New Zealand Society for Earthquake Engineering, 47(4): 253-263. http://dx.doi.org/10.5459/bnzsee.47.4.253-263

[3] Alirezaei, M., Noori, M., Tatari, O., Mackie, K., Elgamal, A. (2016). BIM-based damage estimation of buildings under earthquake loading condition. Procedia Engineering, 145: 1051-1058. http://dx.doi.org/10.1016/j.proeng.2016.04.136

[4] Crespi, P., Franchi, A., Ronca, P., Giordano, N., Scamardo, M., Gusmeroli, G., Schiantarelli, G. (2015). From BIM to FEM: The analysis of an historical masonry building. WIT Transactions on the Built Enviroment, 149: 581-592. http://dx.doi.org/10.2495/BIM150471

[5] Perrone, D., Filiatrault, A. (2018). Use of building information modelling for the seismic design of nonstructural elements. in The XVI European Conferencie on Earthquake Engineering, Thessaloniki, 2018.

[6] Xua, Z., Lub, X., Xiang, Z., Yongji, X., Li, Y. (2019). Seismic loss assessment for buildings with various LODBIM data. Advanced Engineering Informatics, 39: 112-126. https://doi.org/10.1016/j.aei.2018.12.003

[7] Villa, V., Domaneschi M., Cimellaro, G.P. (2018). BIMbased approach for seismic risk analysis. in The Fourth Australasia and South-East Asia Structural Engineering and Construction Conference, Brisbane.

[8] Muñoz-La Rivera, F., Vielma, J., Herrera, R. Carvallo, J. (2019). Methodology for Building Information Modeling (BIM) Implementation in Structural Engineering Companies (SEC). Advances in Civil Engineering, 13: 116. https://doi.org/10.1155/2019/8452461

[9] Seismosoft, SeismoStruct 2018 - A computer program for static and dynamic nonlinear analysis of framed structure. [Online]. Available: http://www.seismosoft.com.

[10] Fajfar, P., Gašperšič, P. (1996). The N2 method for the seismic damage analysis of RC buildings. Earthquake Engineering and Structural Dynamics, 25: 31-46. http://dx.doi.org/10.1002/(SICI)10969845(199601)25:1\%3C31::AID-EQE534\%3E3.0.CO;2$\mathrm{V}$

[11] Vamvatsikos, D., Cornell, A. (2006). Direct estimation of the seismic demand and capacity of oscillators with multi-linear static pushovers through IDA. Earthquake Engineering and Structural Dynamics, 35: 1097-1117. http://dx.doi.org/10.1002/eqe.573

[12] Vielma, J., Mulder, M. (2018). Improved procedure for determining the ductility of buildings under seismic loads. Revista Internacional de Métodos Numéricos para cálculo y diseño en Ingeniería, 34: 1-27. http://10.23967/j.rimni.2018.03.001

[13] Vamvatsikos, D., Cornell, A. (2002). Incremental dynamic analysis. Earthquake Engineering and Structural Dynamics, 31: 491-514. http://dx.doi.org/10.1002/eqe.141

[14] FEMA, Quantification of Building Seismic Performance Factors. FEMA P-695, Washington, D.C.: Federal Emergency Management Agency, 2009. 